\title{
MAPAS DA CLIMATOLOGIA, BASES TEÓRICO-METODOLÓGICAS
}

\section{Maps of Climatology, Teoretical and Methodological Bases}

\author{
Prof. Dr. Ivanilton José de Oliveira \\ Universidade Federal de Goiás \\ Campus Samambaia, Prédio do IESA/IQ2, Sala 19, CEP: 74001-970 - Goiania (GO), Brasil \\ Tel/Fax: (+ 55 62) $35211170 / 35211184$ - ivanilton.oliveira@gmail.com \\ Msc. Diego Tarley Ferreira Nascimento \\ Universidade Federal de Goiás \\ diego.tarley@gmail.com
}

\section{$a \boldsymbol{a}_{a a}$}

\begin{abstract}
Resumo
A representação cartográfica do clima ou das condições atmosféricas momentâneas (tempo) possui uma longa trajetória histórica, com os primeiros mapas surgindo já no século XVII. Assim como os demais mapas temáticos, as representações climáticas (ou meteorológicas) atendiam às necessidades da ciência, que se sistematizava, e às aplicações práticas, como a orientação às navegações, a compreensão da dinâmica das chuvas para a agricultura, entre outras inúmeras possibilidades. O presente trabalho analisa as formas de representação cartográfica do clima, com base em exemplares históricos e também da atualidade, em que há uma profusão de dados sobre o clima, de relativa acessibilidade (como os produtos de sensores remotos e os dados obtidos em estações meteorológicas automáticas), associada à ampliação substancial dos meios para sua representação gráfica, como o uso dos sistemas de informações geográficas (SIG). A despeito disso, observa-se uma carência de sistematização, de padronização nos procedimentos relativos à construção dos mapas, muito embora existam referências históricas e orientações semiológicas para tanto - como aquelas oriundas dos estudos da Semiologia Gráfica. Essas indicações são demonstradas no presente trabalho, com base em exemplos de representações tanto da climatologia analítica, quanto da climatologia dinâmica.
\end{abstract}

Palavras-chave: Cartografia, clima, representação gráfica, convenções cartográficas.

\begin{abstract}
The cartographic representation of the climate or the weather has a long historical trajectory, with the first maps appearing in the seventeenth century,. Like the other thematic maps, the climate (or weather) representations met the needs of science, which is systematized, and the practical applications such as navigation guidance, the understanding of the dynamics of rainfall for agriculture, among many other possibilities. This paper analyzes the forms of cartographic representation of the climate, based on historical and current examples examples, where there is a wealth of data about the climate, of relative accessibility (such as remote sensing and the data from automatic meteorological stations), associated the substantial expansion of the means for their graphical representation, such as the use of geographic information systems (GIS). Despite this, there is a lack of systematization, of standardization of procedures for the construction of the maps, although there are historical references and guidelines for both semiological - such as those derived from studies of Graphic Semiology. These statements are demonstrated in this work, based on examples of representations of as the analytical climatology, as dynamics climatology.
\end{abstract}

Key words: Cartography, climate, graphical representation, cartographic conventions.

\section{Résumé}

La représentation cartographique du climat ou la météo momentanée (temps) a une longue trajectoire historique, avec les premières cartes figurant dans le dix-septième siècle. Comme les autres cartes thématiques, des représentations (ou des conditions météorologiques) répond aux besoins de la science, qui est systématisée, et les applications pratiques telles que l'orientation de navigation à la compréhension de la dynamique de la pluie pour l'agriculture, parmi beaucoup d'autres possibilités. Cet article analyse les formes de représentation cartographique du climat, fondée sur des exemples historiques et aussi actuels, où il ya une foule de données sur le climat de l'accessibilité relative (comme la télédétection et des données provenant des stations météorologiques automatiques), associés à l'expansion considérable de leurs moyens de représentation graphique, comme l'utilisation des systèmes d'information géographique (SIG). Malgré cela, il ya un manque de systématisation, de standardisation des procédures pour la construction des cartes, bien qu'il existe des références historiques et des lignes directrices sémiologiques à cet effet - telles que celles provenant d'études de sémiologie graphique. Ces déclarations sont mises en évidence dans ce travail, basé sur des exemples de représentations de la climatologie analytique et de la dynamique des phénomènes météorologiques.

Mots clés: Cartographie, le climat, la représentation graphique, conventions cartographiques.

$$
\text { åOa }
$$

Revista da ANPEGE, v. 7, n. 7, p. 127 -141, jan./jul. 2011.

ISSN 1679-768 X @ (2003, Associação Nacional de Pesquisa e Pós-Graduação em Geografia. Todos os direitos reservados. 


\section{INTRODUÇÃO}

Em tempos de aquecimento global - malgrado as intermináveis discussões sobre dados que o corroborem ou não -, as preocupações com o clima estão cada vez mais presentes no dia-a-dia, em todas as esferas da sociedade. Comentar as mudanças climáticas, percebidas ou de fato registradas, tem se tornado verdadeira obsessão nos meios de comunicação. Da mesma forma como observar e compreender a previsão do tempo, apresentada em telejornais ou consultada em sites especializados, é algo que já se torna rotina para um número cada vez maior de pessoas. Obviamente, isso tem se respaldo no fato de o clima afetar a todos - embora não da mesma forma ou com as mesmas consequências.

A palavra clima, etimologicamente, origina-se do vocábulo grego klima, que significa "inclinação", em alusão à curvatura da superfície da Terra. Isto porque os gregos acreditavam que as diferenças do clima só ocorriam de norte para o sul originando as zonas tórridas, temperadas e frígidas (VIANELLO; ALVES, 2000). Hann (1882, apud BARROS; ZAVATTINI, 2010, p. 256) considera o clima como sendo "o conjunto de fenômenos meteorológicos que caracterizam o estado médio da atmosfera em um ponto da superfície terrestre", conceito este, segundo Barros e Zavattini (2010), que encara o clima como sendo uma média, uma abstração, sendo incapaz de revelar a realidade de forma concreta. Nas palavras de Sorre (2006, p. 90), o clima representa a "o ambiente atmosférico constituído pela série de estados atmosféricos acima de um dado lugar em sua sucessão habitual", conceito este que considera os estados da atmosfera em sua totalidade. A definição da Organização Meteorológica Mundial (1959) indica que o clima é um conjunto flutuante de condições atmosféricas, caracterizadas pelos estados e evolução do tempo no curso de um período suficientemente longo, em um determinado domínio espacial.

Convém então destacar a diferença existente entre clima e tempo, já que este último representa uma combinação transitória, concreta, de comportamentos dos elementos, como a temperatura, a umidade, a pluviosidade, o vento, a insolação etc., caracterizando, assim, um estado atmosférico momentâneo (CONTI; FURLAN, 1996). Para Sorre (2006, p. 90), cada um desses estados

caracteriza-se pelas suas propriedades dinâmicas e estáticas da coluna atmosférica, composição química, pressão, tensão dos gases, temperatura, grau de saturação, comportamento quanto aos raios solares, poeiras ou matérias orgânicas em suspensão, estado do campo elétrico, velocidade de deslocamento das moléculas etc.

Clima e tempo são objetos de estudo de duas ciências irmãs: a climatologia e a meteorologia. A primeira é um ramo da geografia física, mais afeita ao entendimento dos processos e mecanismos atmosféricos e dos elementos climáticos e a interação desses com a superfície terrestre, verificados durante um longo período de tempo (normalmente trinta anos), sempre considerando sua distribuição espacial. Já a meteorologia é uma ciência mais relacionada à física, responsável pelo entendimento dos fenômenos físicos que ocorrem na atmosfera, sempre atentando para "a medida desses fenômenos, as condições físicas em que são produzidos, a natureza das relações que existem entre eles e os fatores que os condicionam" (SORRE, 2006, p. 89).

De acordo com Sorre (2006, p. 89), a chamada climatologia clássica ou tradicional, também conhecida por separativa ou analítica, foi, sobretudo, obra de meteorologistas. Nessa vertente o clima é estudado, compreendido e representado com base em seus elementos constituintes - quais sejam: a temperatura do ar, a pressão, a umidade, as precipitações, o vento, a insolação e a nebulosidade - separadamente, empregando-se exageradamente de médias e possuindo, por isso, um caráter essencialmente quantitativo (BARROS; ZAVATTINI, 2009).

Outra corrente da climatologia, conhecida por climatologia dinâmica, ou sintética, advoga a necessidade de uma visão integrada dos elementos atmosféricos, com papel de destaque para os movimentos das massas de ar. Há uma preocupação com a síntese, articulando os elementos atmosféricos vistos em sua dinâmica, isto é, não em momentos estanques e sim como processos. Derivam dessa proposta as representações de zonas climáticas, agrupadas conforme semelhança em seus 
elementos climáticos, fisiográficos ou sistemas atmosféricos atuantes, a exemplo da classificação climática proposta por Strahler (1975).

$\mathrm{O}$ advento das grandes explorações geográficas promovidas pelos europeus, a partir do século $\mathrm{XV}$, significa um marco na representação cartográfica do clima. Anteriormente a essa fase, as referências aos elementos climáticos eram apenas indiretas ou tinham mais cunho simbólico. É o caso dos inúmeros mapas com indicações dos ventos, retratados pictoricamente, nas margens dos mapas (Figura 1).

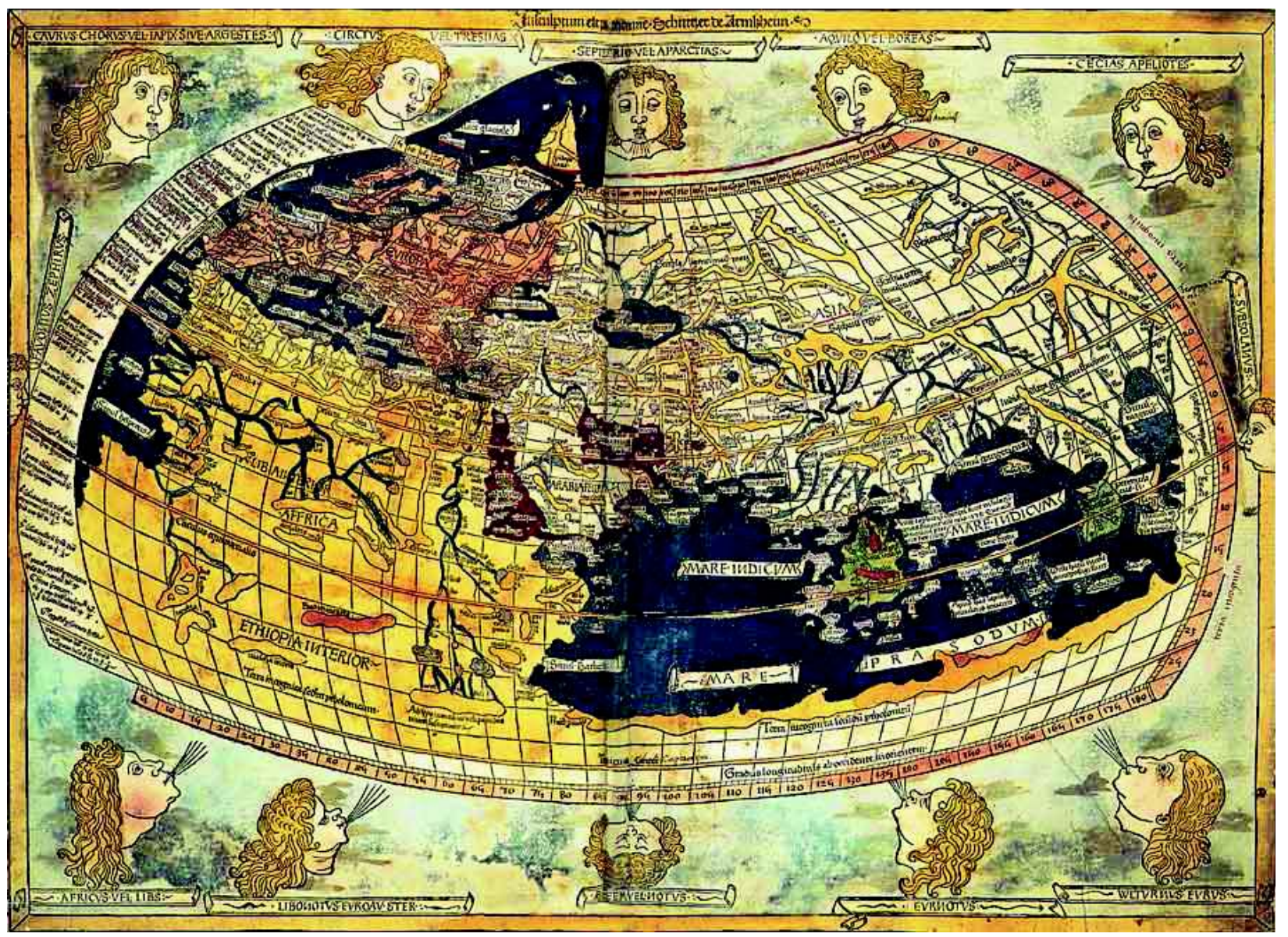

Figura 1 - Reprodução medieval do Mapa de Ptolomeu, Séc. II d.C. Fonte: $<$ http://www.pime.org.br/imagens/dez2001-f20e21.jpg>.

De acordo com Martinelli (2010, p. 2), o mapa dos ventos oceânicos de Halley, de 1688 (Figura 2), é considerado como o primeiro mapa temático, bem como o primeiro mapa meteorológico. Halley teve o cuidado de usar como base o planisfério na projeção de Mercator, o que permitiu registrar os ventos em suas verdadeiras direções.

Já no fim do século XVIII, observações de temperatura e outros fenômenos meteorológicos eram registrados em mapas, porém apenas mediante a inserção dos valores inscritos sobre o mapa. Foi Humboldt que, em 1817, adaptando o conceito de isolinha idealizado por Halley para a declinação magnética, traçou as isotermas, representando a distribuição em área das temperaturas, método que possibilitou ressaltar que o gradiente de decréscimo da temperatura com o aumento da latitude difere de uma costa para outra, de leste para oeste e vice-versa, nos continentes (MARTINELLI, 2010, p. 2)

Nessa época começam a surgir as primeiras produções cartográficas associadas diretamente à ciência climatológica. Exemplos disso são o mapa de isotermas anuais, publicado em 1817 por 
Alexander von Humboldt (Figura 3), e o mapa mundial de precipitação, elaborado por Heinrich Berghaus, em 1845 (Figura 4).

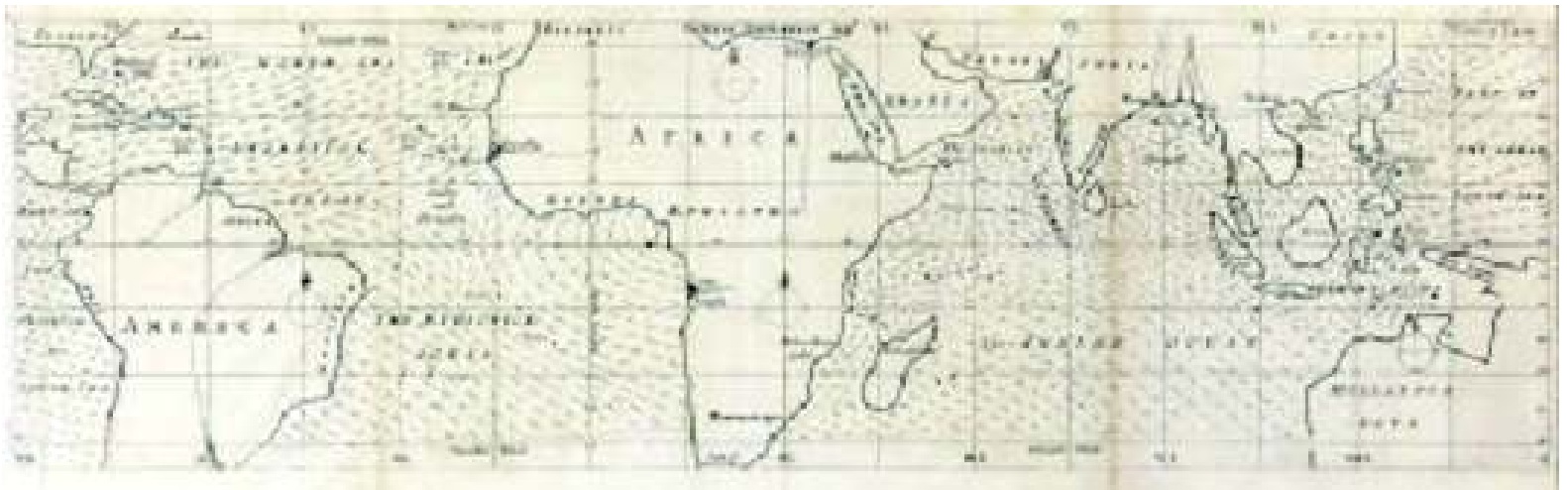

Figura 2: Mapa dos ventos oceânicos elaborado por Halley, em 1688. Fonte: <www.infografe.com.br>.

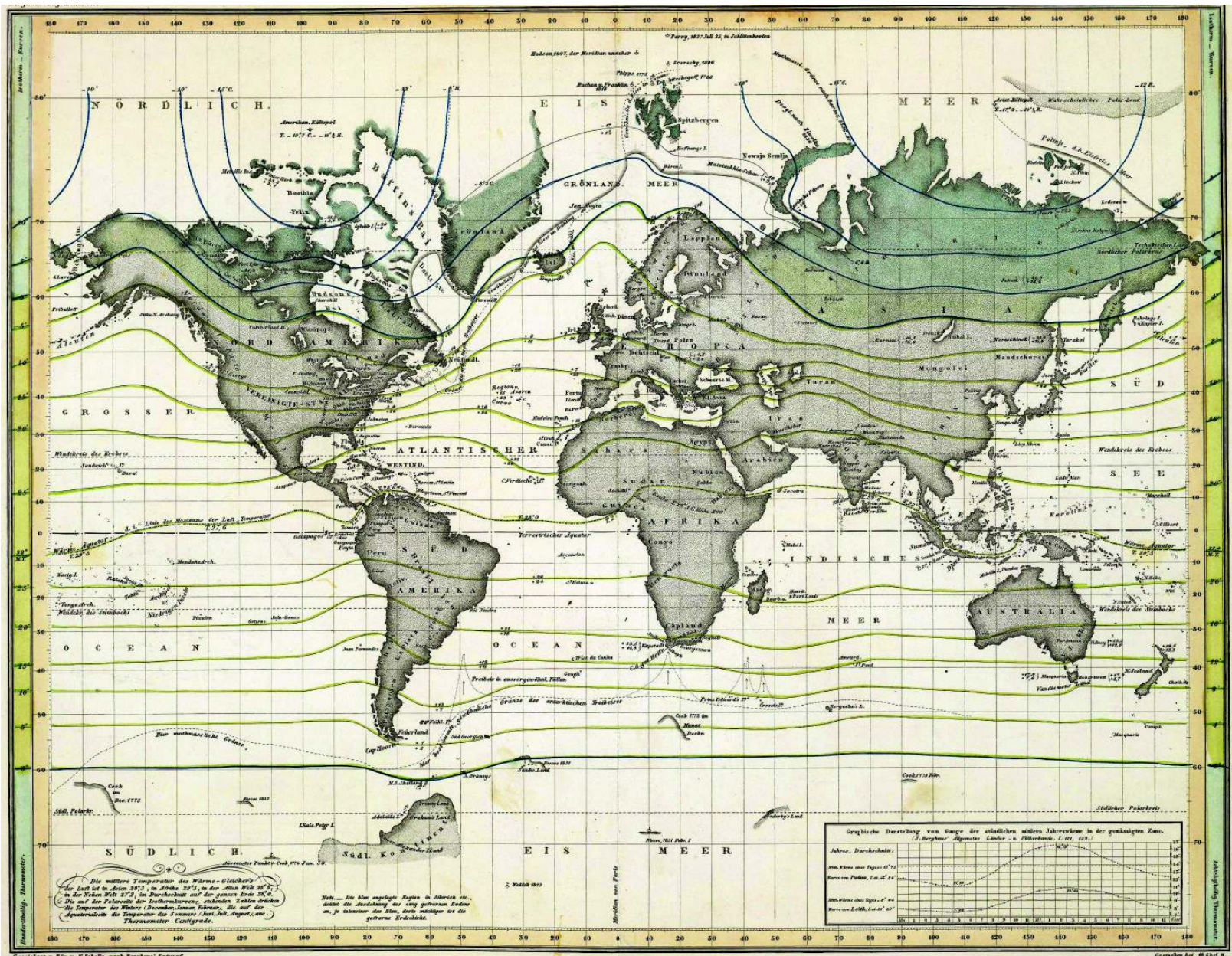

Figura 3: Mapa de isotermas elaborado por Alexander von Humboldt, 1817.

Fonte: $<$ http://www.math.yorku.ca/SCS/Gallery/images/rumsey/berghaus-vonhumbolt.jpg>.

O que se vê, até meados do século XIX, é a utilização majoritária de isolinhas nas representações climatológicas, isto é, linhas de mesmo valor/quantidade, a exemplo das isotermas (linhas com mesmo valor de temperaturas), isóbaras (pressão) e isoietas (precipitação). De acordo com Martinelli (2010, p. 3), por volta de 1850 "as isolinhas com ordem visual intercalar tornaram-se praticamente convencionais para a representação de fenômenos atmosféricos", compondo o chamado método isarítmico. A princípio, com a associação das isolinhas a variações de tonalidades monocromáticas (Figuras 3 e 4), e, já no início do século XX, com o emprego das cores (Figura 5). 


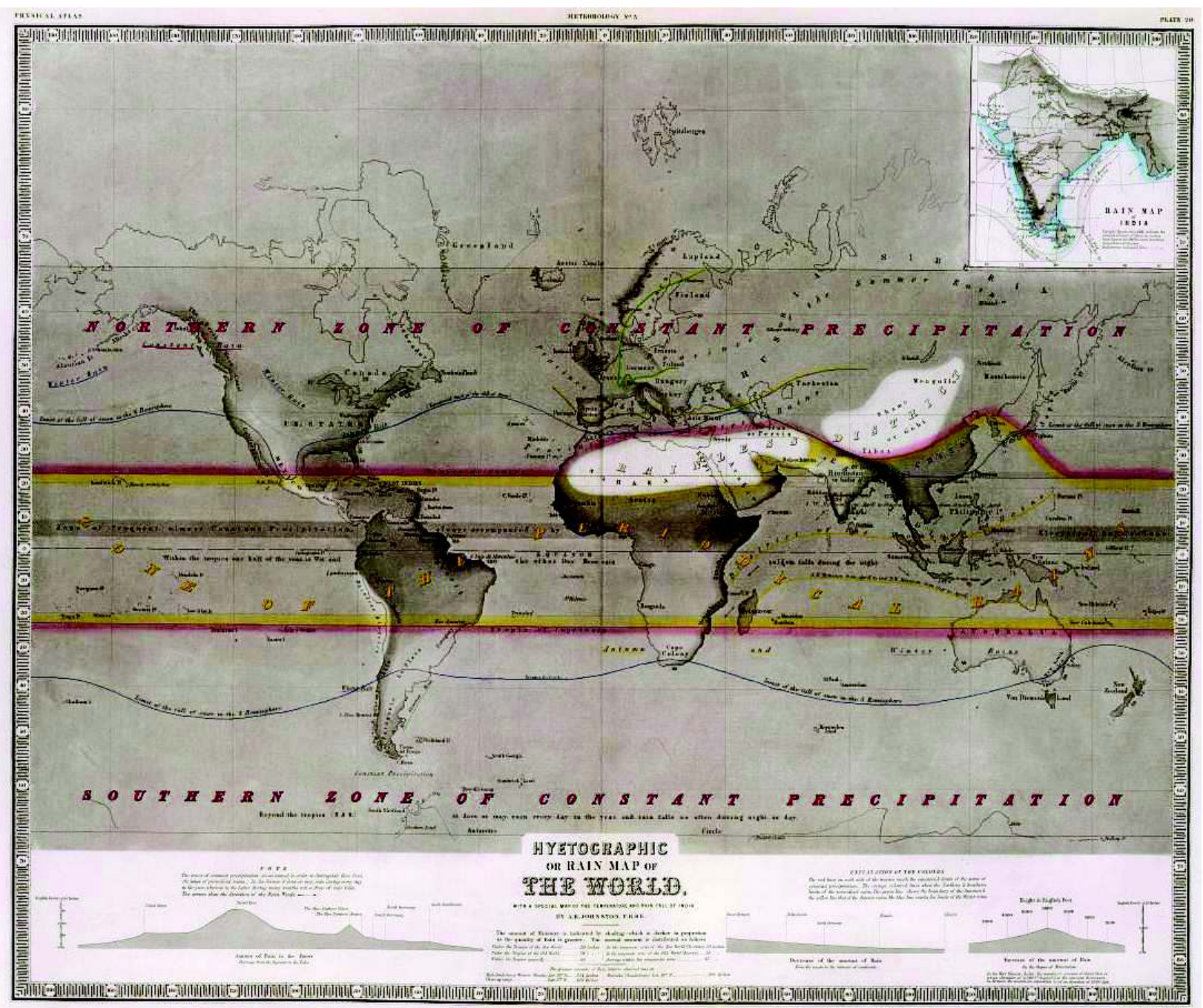

Figura 4: Mapa mundial de precipitação elaborado por Heinrich Berghaus, 1845. Fonte: $<$ http://www.davidrumsey.com $>$.

As representações evoluíram dos fenômenos atmosféricos isolados para tentar abarcar a complexidade do clima. Martinelli (2010) afirma que os "mapas do clima eram entendidos como mapas temáticos complexos por procurar integrar graficamente a estrutura de diversos fenômenos individuais", o que denotava "[...] a ansiedade por uma cartografia que pudesse expressar a compreensão holística da realidade mediante um raciocínio de síntese". A partir de 1970, os estudos da climatologia sintética começaram a ganhar relevância, em comparação com a climatologia separativa. Além do reconhecimento da importância da circulação atmosférica, o ritmo passa a ser elemento norteador da compreensão do clima e dos mecanismos que regem seu funcionamento (MONTEIRO, 1976).

Pode-se falar da existência, na atualidade, de uma grande disseminação e publicação de produtos cartográficos representando dados e informações referentes ao clima ou ao tempo atmosférico (e.g. temperatura, precipitação, umidade, massas de ar etc.), por diversos setores da sociedade, como os meios de comunicação, universidades, órgãos públicos, entre outros. Entretanto, boa parte (senão a maior parte) desses produtos não apresenta qualquer rigor ou observação de normas ou orientações relacionadas à linguagem cartográfica, ao ponto de poderem apresentar erros ou condicionar limitações em suas representações.

Esse processo - de disseminação cartográfica - foi auxiliado pela popularização dos programas de construção cartográfica, como os sistemas de informações geográficas (SIG) de acesso livre e os mapas interativos na Internet, bem como pela disponibilização gratuita de dados climáticos provenientes de Estações Meteorológicas Convencionais e Plataforma de Coleta de Dados (PCD's 
- Estações automáticas), atualmente disponibilizados na Internet. Isso possibilita a qualquer pessoa, com um mínimo de conhecimento, conseguir criar suas próprias representações gráficas (mapas e gráficos).

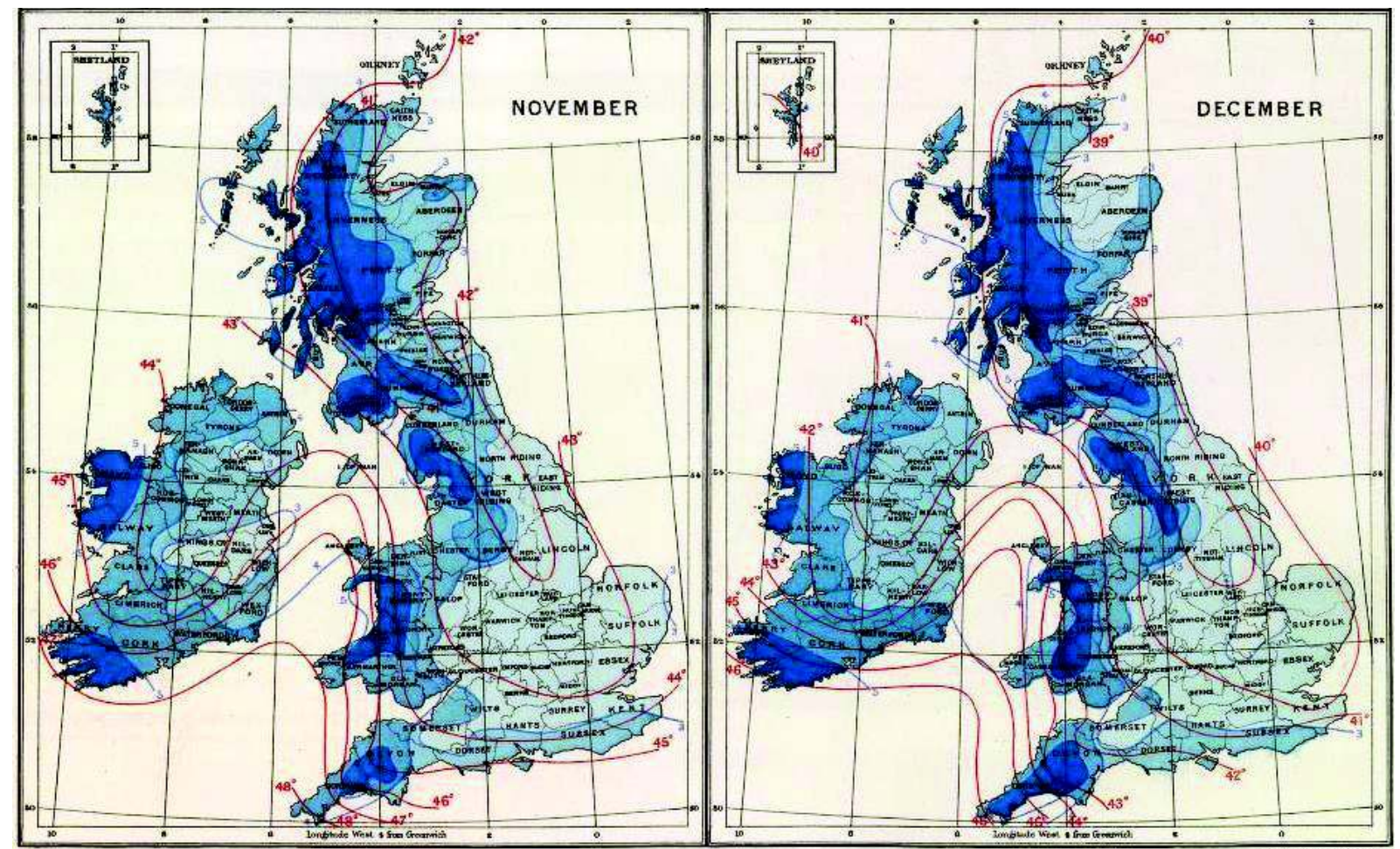

Figura 5: Mapas das médias mensais de precipitação e temperatura do ar das Ilhas Britânicas, em novembro e em dezembro, elaborados por Alexander Buchan, 1901. Fonte: <http://www.davidrumsey.com>.

É preciso destacar, ainda, o fato de a representação cartográfica do clima ter se beneficiado enormemente dos avanços tecnológicos oriundos da chamada "corrida espacial", originada na década de 1950, que opôs os Estados Unidos (EUA) e a então União Soviética, numa competição tecnológica pela conquista do espaço sideral que resultou no desenvolvimento de foguetes, naves e satélites artificiais. "Cinquenta anos atrás, o primeiro satélite meteorológico do mundo partiu do Cabo Canaveral, Flórida, abrindo uma nova e emocionante dimensão na previsão do tempo", conforme é enfatizado por Cole, Leslie (2010). Tratava-se do satélite TIROS 1 (de Television Infrared Observation Satellite), lançado pelos EUA.

Esse satélite mudou para sempre a previsão do tempo e a investigação científica do clima. Graças à parceria entre a agência espacial norte-americana, NASA(National Aeronautics and Space Administration) e a NOAA (National Oceanic and Atmospheric Administration), outras séries de satélites foram lançados, dando aos cientistas a capacidade de acompanhar as mudanças no clima, desde o início sutil de uma seca e seu impacto sobre a vegetação até o monitoramento da temperatura global na superfície do mar, sinalizando fenômenos atmosféricos como o El Niño e La Niña (COLE; LESLIE, 2010).

As imagens dos sensores remotos serviram à representação espacial do tempo atmosférico e, por consequência, à cartografia do clima, na medida em que o monitoramento dos componentes climáticos (massas de ar, temperaturas etc.) ganhou uma dimensão espacial e temporal jamais obtida até então, com os registros pontuais oriundos das estações meteorológicas.

Dentre as vantagens dos sensores remotos, podem se citar a resolução espacial, capaz de cobrir toda a superfície terrestre, permitindo análises globais, mas também as regionais e/ou locais; os registros temporais constantes, fornecendo dados históricos e sinópticos, que permitem o monitoramento; e, por fim, a relativa facilidade de aquisição dos registros, em função dos acervos dispo- 
nibilizados por agências e órgãos governamentais. As informações geradas abarcam desde mapas da radiação solar e terrestre, às cartas de índices ultravioleta (IUV), de classificação de nuvens, queimadas, temperatura da superfície do mar (TSM) e terrestre (TST), sondagens atmosféricas, sistemas convectivos e tempestades, precipitações, nevoeiros, ventos, temperatura de brilho, entre outras.

Embora essa disseminação cartográfica represente um avanço, há que se destacar os problemas advindos da inobservância das regras básicas existentes para a construção de representações gráficas. Além do uso de bases cartográficas confiáveis, pela adequação de escalas, projeções, sistemas de coordenadas etc., os mapas climáticos devem ser vistos como mapas temáticos e, portanto, devem pautar-se pela excelência na comunicação daquilo que pretendem informar. Para tanto, precisam seguir as regras oriundas da Semiologia Gráfica (BERTIN, 1967).

O presente trabalho pretende contribuir nesse sentido, ao realizar uma discussão acerca do uso da cartografia na representação dos dados e informações de cunho climatológico, apresentando exemplos de mapas com o intuito de observar o rigor técnico em sua elaboração, tendo em vista os preceitos já estabelecidos no âmbito da comunicação cartográfica.

\section{REFERENCIAIS TEÓRICO-METODOLÓGICOS}

A análise aqui apresentada é pautada na busca da interface, necessária e imprescindível, entre a produção científica no âmbito da climatologia (e da meteorologia) e os conhecimentos desenvolvidos no escopo da Cartografia Temática, ramo da Cartografia que se ocupa da compreensão dos mapas como meios de comunicação, ou seja, da existência de uma linguagem cartográfica. Os mapas climáticos, como qualquer mapa temático, devem cumprir a função de transmitir uma mensagem ao seu usuário, de forma clara e coerente com aquilo que se propõe a abordar, conforme concebido por quem produziu o mapa.

As regras da Semiologia Gráfica (BERTIN, 1967), que orientam a construção de representações gráficas, como mapas e diagramas, podem ser sintetizadas pela Tabela de Variáveis Visuais, também chamadas variáveis da imagem ou da retina (Figura 6).

Conforme Oliveira (2005), essa tabela indica quais signos são mais adequados dependendo das relações a serem transcritas. Como é possível observar, há duas variáveis de localização no plano (X e Y), duas variáveis formadoras da imagem (tamanho e valor) e outras cinco variáveis de separação (grão ou granulação, cor, orientação e forma). Cada uma dessas variáveis pode, ainda, ser modulada como pontos, como linhas ou como áreas em um mapa. Por sua vez, cada variável é mais adequada para expressar determinado tipo de relação entre objetos/fenômenos: tamanho é a única variável indicada para expressar relações de proporção (quantitativas); valor ou intensidade é a mais indicada para expressar relações de hierarquia (ordenadas); e granulação, cor, forma e orientação devem ser usadas para transcrever relações de diversidade (seletividade). Outros autores, como Robinson et al. (1995) e Slocum et al. (2009) apresentam pequenas modificações nessas referências, acrescentando variáveis (como o 'espaçamento') ou redefinindo algumas delas (como a distinção de 'matiz', 'saturação' e 'valor' da variável cor).

De acordo com Bertin (1967), na construção de representações gráficas, como os mapas temáticos, a ênfase na concepção da legenda deve ser dada às relações entre os objetos e/ou fenômenos que serão cartografados e não necessariamente à relação entre significante (o símbolo) e significado (a ideia), expressa na legenda. Envolve, portanto, ressaltar a compreensão e representação das relações originais expressas na informação (nos dados). Dessa forma, busca-se atingir o objetivo da monossemia, ou seja, que as relações entre os dados sejam representadas por relações de mesma natureza. A opção contrária, isto é, a ênfase na relação entre significante-significado dá margem à polissemia, em que o mapa construído acaba necessariamente por permitir diferentes compreensões da informação que se pretende transmitir, podendo até mesmo alterar completamente a ideia original (OLIVEIRA, 2005). 

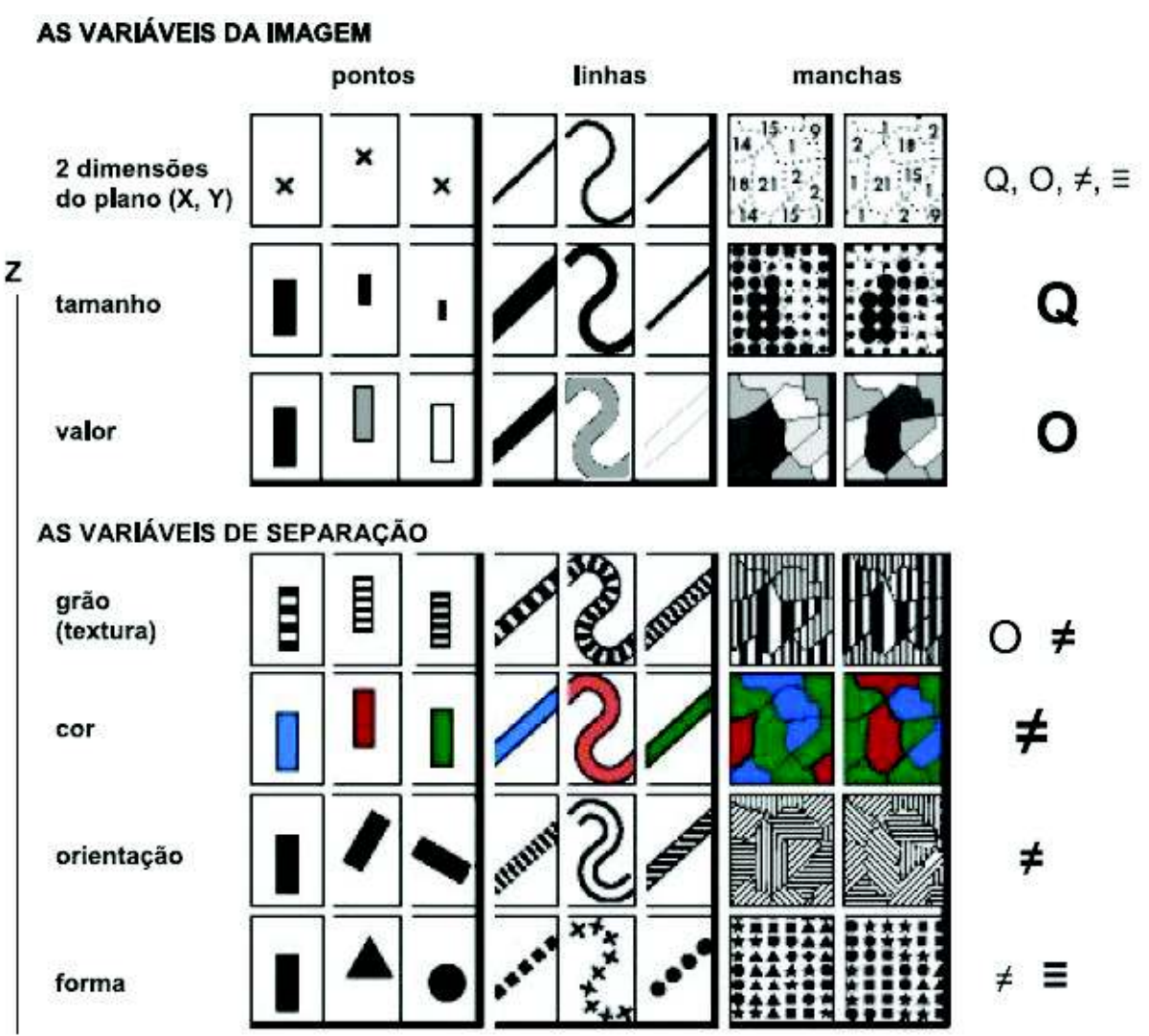

Figura 6 - As variáveis visuais de J. Bertin (1967). Disponível em: <http://www.sciences-po.fr/cartographie/ cartographie_html/5_page5theorie/graphique_bertin2001>. Adaptada.

Nos mapas, as relações entre objetos/fenômenos podem ser expressas em uma das seguintes naturezas: a) relações quantitativas, quando os dados são numéricos e permitem estabelecer proporção entre os objetos/fenômenos; b) relações de ordem, quando os dados não permitem estabelecer proporção, mas apresentam uma hierarquia visível entre os objetos/fenômenos; e c) relações seletivas, quando os dados não permitem estabelecer relações de ordem ou de proporção. Portanto, os objetos/fenômenos são apenas diferentes (ou semelhantes) entre si.

Dessa forma, os mapas climáticos que venham a ser elaborados, sejam aqueles oriundos da climatologia separativa, sejam os da climatologia dinâmica, ou ainda as cartas sinópticas, da meteorologia, independentemente dos recursos e dados utilizados em sua construção, sejam eles coletados em estações meteorológicas ou gerados por sensores remotos, todos devem observar as mesmas regras, na escolha e uso dos signos que comporão a legenda e serão empregados no mapa.

Assim como os demais mapas temáticos, os mapas da climatologia devem se basear nas regras da Semiologia Gráfica, essencialmente no que concerne ao emprego das variáveis visuais na tarefa de retratar a natureza das relações existente entre os dados climáticos. As escalas de mensuração dos dados climáticos, por sua vez, refletem um claro predomínio de representações ordenadas ou seletivas, com o emprego das variáveis visuais valor (para o primeiro caso), cor e forma (para o segundo).

A representação de dados climáticos na forma de mapas geralmente parte da implantação pontual (baseada em dados de estações meteorológicas, aparelhos ou miniabrigos), para uma implantação linear, na forma de isolinhas (isoietas, isóbaras, isotermas), para então serem traduzidas em representações zonais, demonstrando um continuum espacial .

Destaca-se que a representação pontual se traduz em uma maior fidelidade aos dados originais, apresentando, contudo, pouca representatividade espacial; enquanto a representação zonal acarreta 
uma forte generalização cartográfica, por inferir valores para locais sem registros de dados. O método de implantação exclusivamente pontual é raramente utilizado, salvo quando há uma pequena rede de estações meteorológicas ou ainda para apresentar informações mais simples de localizações específicas, a exemplo de temperaturas em cidades turísticas.

A seguir são apresentados e analisados alguns exemplos de mapas cuja construção temática expressa as diferentes possibilidades no emprego dos modos de implantação e das variáveis visuais.

\section{ANÁLISE DE MAPAS CLIMATOLÓGICOS}

As construções cartográficas a serviço da climatologia tanto podem ser analíticas quanto sintéticas. As primeiras se referem a mapas mais afeitos à climatologia separativa, a exemplo de representações das temperaturas (Figura 7) ou das precipitações pluviométricas (Figura 8).

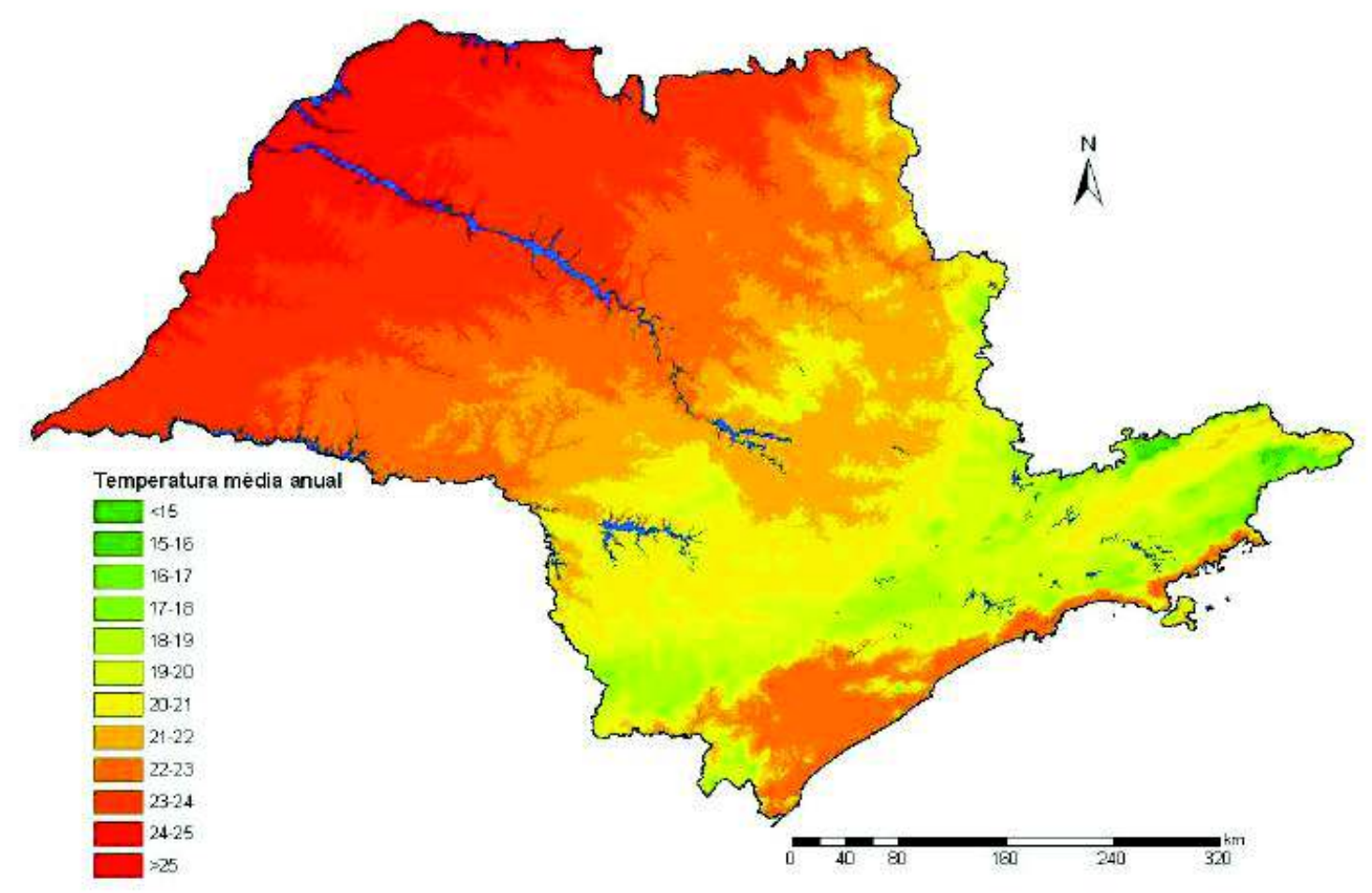

Figura 7: Mapa de temperatura do ar no estado de São Paulo.

Fonte: $<$ http://www.relevobr.cnpm.embrapa.br/conteudo/aplicacoes/temperatura.png>.

Convém observar que, independente do fato de serem representações zonais ou pontuais, esses mapas envolvem dados que expressam uma natureza ordenada, pois devem ressaltar hierarquias visuais, advindas de escalas de mensuração nominal (ordem de base qualitativa) ou de intervalo (ordem de base quantitativa). Portanto, só pode ser empregada a variável visual valor, expressa por uma (ou mais de uma) ordem policromática (entre cores frias ou entre cores quentes), tonalidades monocromáticas (como níveis de cinza ou qualquer outra cor), texturas ou pontos (desde que variando do claro para o escuro).

O uso da variável cor merece destaque, pois ela tem grande poder de atração visual e a ampliação do acesso a produtos cartográficos em meio digital tem facilitado o seu emprego - haja vista o custo envolvido no caso da impressão, o que levava à preferência pelas representações em preto e branco ou monocromáticas. A cor tem grande poder de discriminação e sua percepção é sensivelmente maior, no caso da visão humana, se comparada aos tons de cinza. 


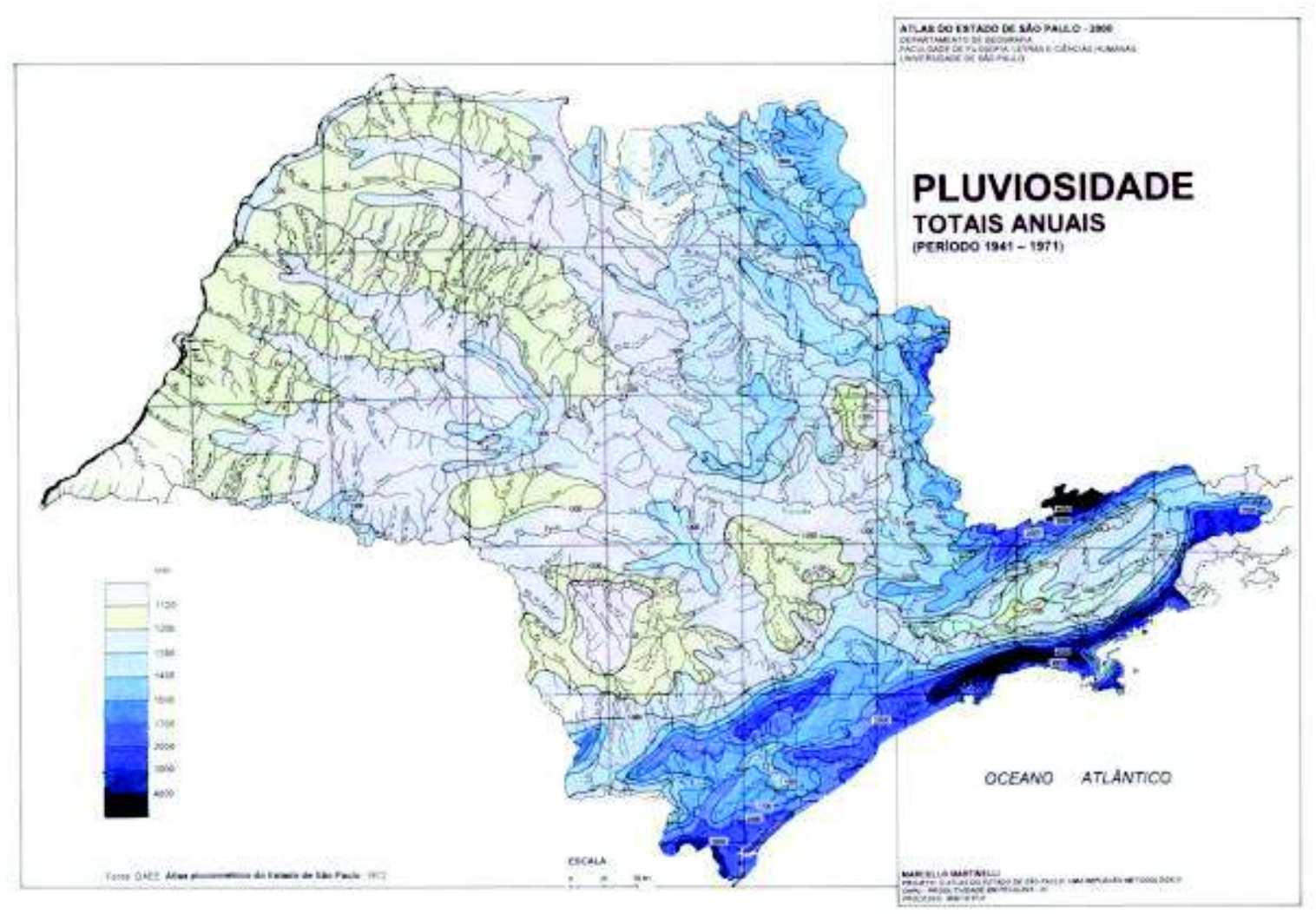

Figura 8: Mapa da pluviosidade total anual no estado de São Paulo. Fonte: Martinelli, 2010.

Entretanto, o uso das cores em mapas deve atentar para a natureza das relações entre os dados. Cores frias (como o violeta, o azul, o verde) criam a ilusão de afastamento, enquanto as cores quentes (vermelho, laranja, amarelo) parecem se aproximar do observador. Portanto, elas são contrastantes entre si e mesclá-las (azul, vermelho, verde, amarelo) cria a noção de diversidade - desde que se mantenham com a mesma intensidade visual.

Por sua vez, é possível obter uma ordem visual utilizando tons de uma mesma cor - como azul escuro, azul médio, azul claro (Figura 8) - ou seguindo a ordem cromática existente no espectro eletromagnético, quando da decomposição da luz branca, isto é, a sequência do arco-íris. Ela contrapõe as cores frias, de um lado, às cores quentes, do outro (Figura 7).

No caso das representações lineares, comuns na meteorologia, também devem ser observadas essas regras. Um exemplo seria a contraposição de valores opostos, como frio versus quente (Figura 9), com o emprego de representações lineares com valores visuais também opostos no espectro das cores, como o vermelho e o azul. Assim, as frentes devem ser representadas pela combinação de linhas e formas geométricas convencionais (triângulos) em azul, quando se trata de frente fria; ou em vermelho (linha e semicírculo), quando se trata de frente quente. Também as simbologias pontuais devem acompanhar tal atribuição simbólica, a exemplo das convenções cartográficas para representação dos centros de pressão atmosférica (vermelho para os centros de baixa pressão e azul para os centros de alta pressão).

.O valor simbólico, aliás, não pode ser desconsiderado. É possível mesmo falar em convenções existentes pela tradição cartográfica. É o caso do emprego da cor azul para as representações que envolvem umidade ou precipitação pluviométrica; dos tons de violeta, para as baixas temperaturas; das cores quentes para temperaturas elevadas ou do branco para precipitação nival. Entretanto, isso não impede o uso de outras cores, desde que corretamente trabalhadas - embora possa vir a causar estranheza ver um mapa de chuvas representado por tons de verde ou de marrom. 


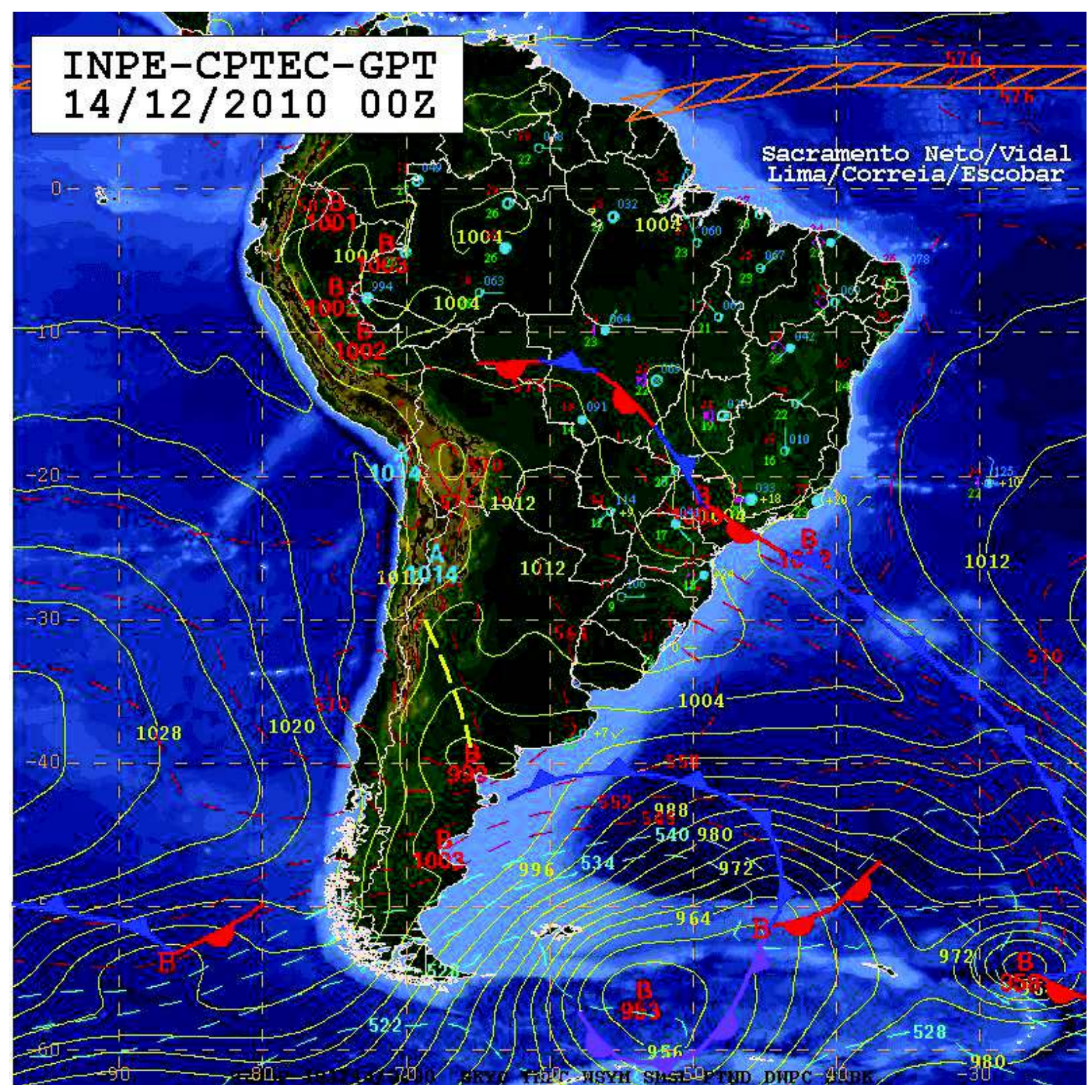

Figura 9: Carta sinótica da América do Sul.

Fonte: CPTEC/INPE. Disponível em: <http://img0.cptec.inpe.br/ rgptimg/Produtos-Pagina/Carta-Sinotica/Analise/ Superficie/superficie_2010121400.gif>.

Os cartogramas ou mapas diagramas, também muito comuns na climatologia (Figura 10), conquanto possibilitem "georreferenciar" valores de temperatura e/ou precipitação, conjugando pluviogramas a bases cartográficas, acabam gerando mapas que precisam ser lidos ao invés de vistos. Dessa forma, a análise comparada dos próprios pluviogramas, desde que todos mantendo as mesmas escalas (nas classes de temperatura e de precipitação), já seria suficientemente clara para uma compreensão das relações existentes.

As representações iconográficas (Figura 11), por sua vez, muito utilizadas nos meios de comunicação, têm papel de destaque na transcrição direta dos significados, já que reportam diretamente ao fenômeno que é retratado no mapa, como o desenho de um sol para indicar tempo estável ou o desenho de uma nuvem com pingos de chuva, para indicar a possibilidade de precipitação pluviométrica.

Os maiores problemas desse tipo de mapa são os riscos inerentes à criação de símbolos que consigam retratar todo o espectro de fenômenos atmosféricos e, ao mesmo tempo, consigam manter o poder de conectar, na mente do usuário do mapa, o símbolo à ideia correta, isto é, o fenômeno 
representado. Pode-se exemplificar tal dificuldade com base em elementos como os diferentes tipos de ventos, de nuvens, de precipitações etc. Outro risco, por vezes negligenciado, é a exaustão visual, pela superposição de inúmeros fenômenos/símbolos, ao invés da opção pelos mapas analíticos ou que conjuguem menor número de elementos.

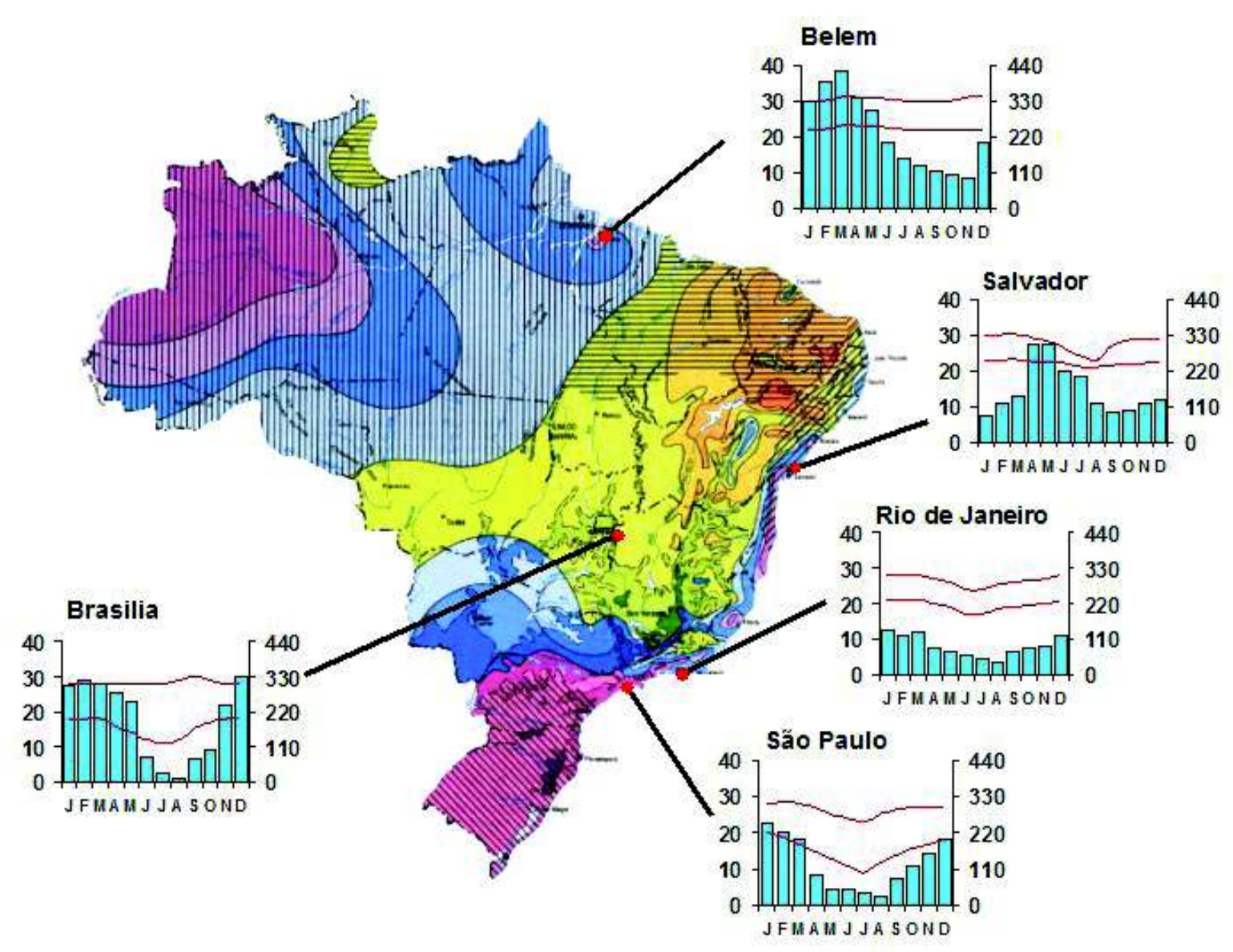

Figura 10: Mapa climático do Brasil, segundo a classificação de Thornthwaite, combinado a pluviogramas representativos de cada "tipo climático".

Fonte: <http://www.brazadv.com/images/mapa_clima_1.jpg>.

As cartas de síntese (Figura 12), relacionadas à climatologia dinâmica, embora representem um avanço na tentativa de expressar cartograficamente a complexidade de integração dos fenômenos climáticos, correm o risco de se tornar mapas exaustivos, pela conjugação ou justaposição de inúmeras informações, gerando legendas extensas e, muitas vezes, quase impossíveis de serem reconhecidas de forma instantânea pelo usuário do mapa.

Tais mapas são, por sua própria natureza, representações seletivas, isto é, não devem atribuir maior ou menor importância a este ou àquele símbolo (e, por consequência, a este ou aquele lugar) retratado no mapa. Deve, assim, fazer uso das cores (alternando cores frias e quentes), das texturas, das orientações e/ou das formas (símbolos). Claro que, quanto maior o número de classes a serem representadas, mais difícil ficará a obtenção do contraste entre os signos da legenda (e no mapa) sem gerar uma variação de valor visual entre eles.

Também a própria dinâmica climática tem lugar na representação cartográfica. É o caso dos mapas que buscam retratar os movimentos das massas de ar (Figura 13) ou da direção e intensidade de ventos. Mostram, assim, uma relação de movimento no espaço. Mas também podem ser construídos para representar a movimentação ao longo do tempo. A cartografia em meio digital caminha nessa direção, ao permitir simular tais movimentos, algo já existente nos sites que representam 
cartas-imagens com os deslocamentos das massas de ar ao longo de horas ou o desenvolvimento de fenômenos como furacões e tufões.

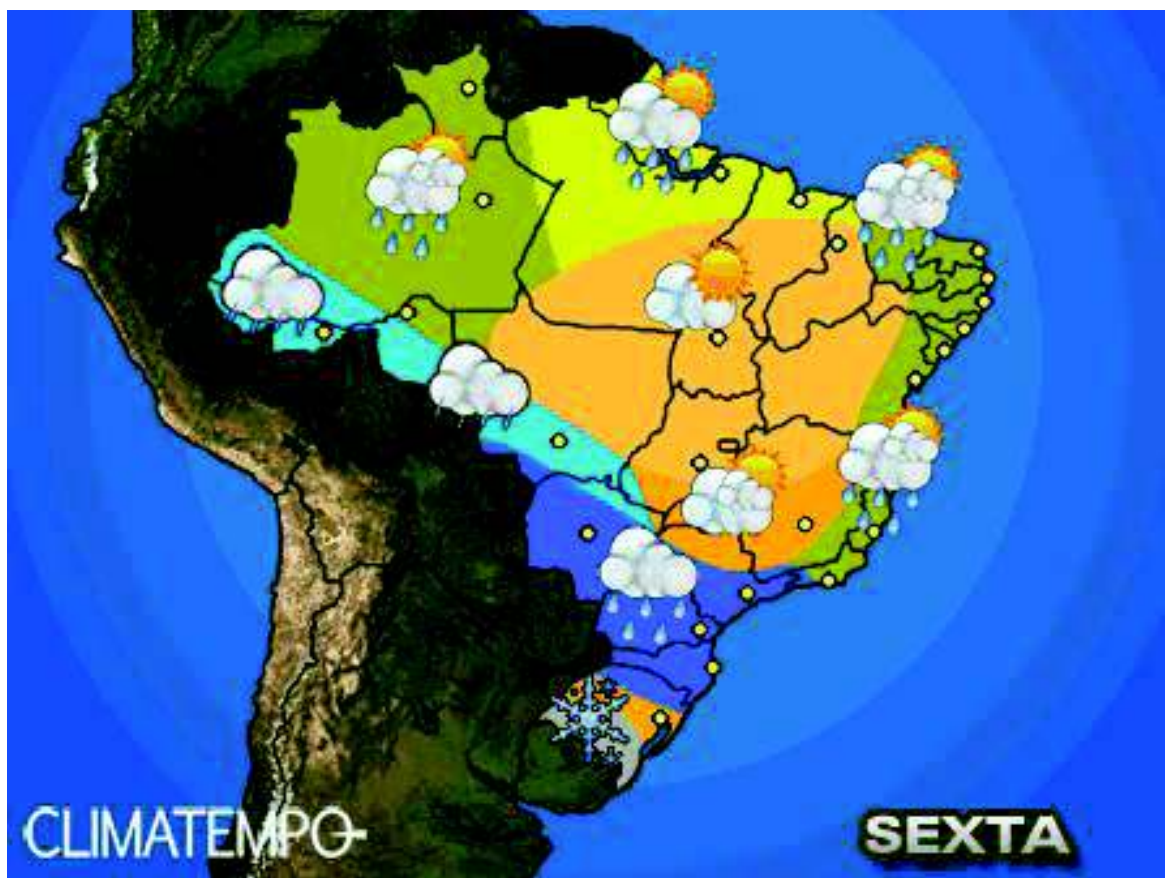

Figura 11: Mapa de previsão do tempo para o Brasil.

Fonte: <http://www.climatempo.com.br/brasil.php $>$.

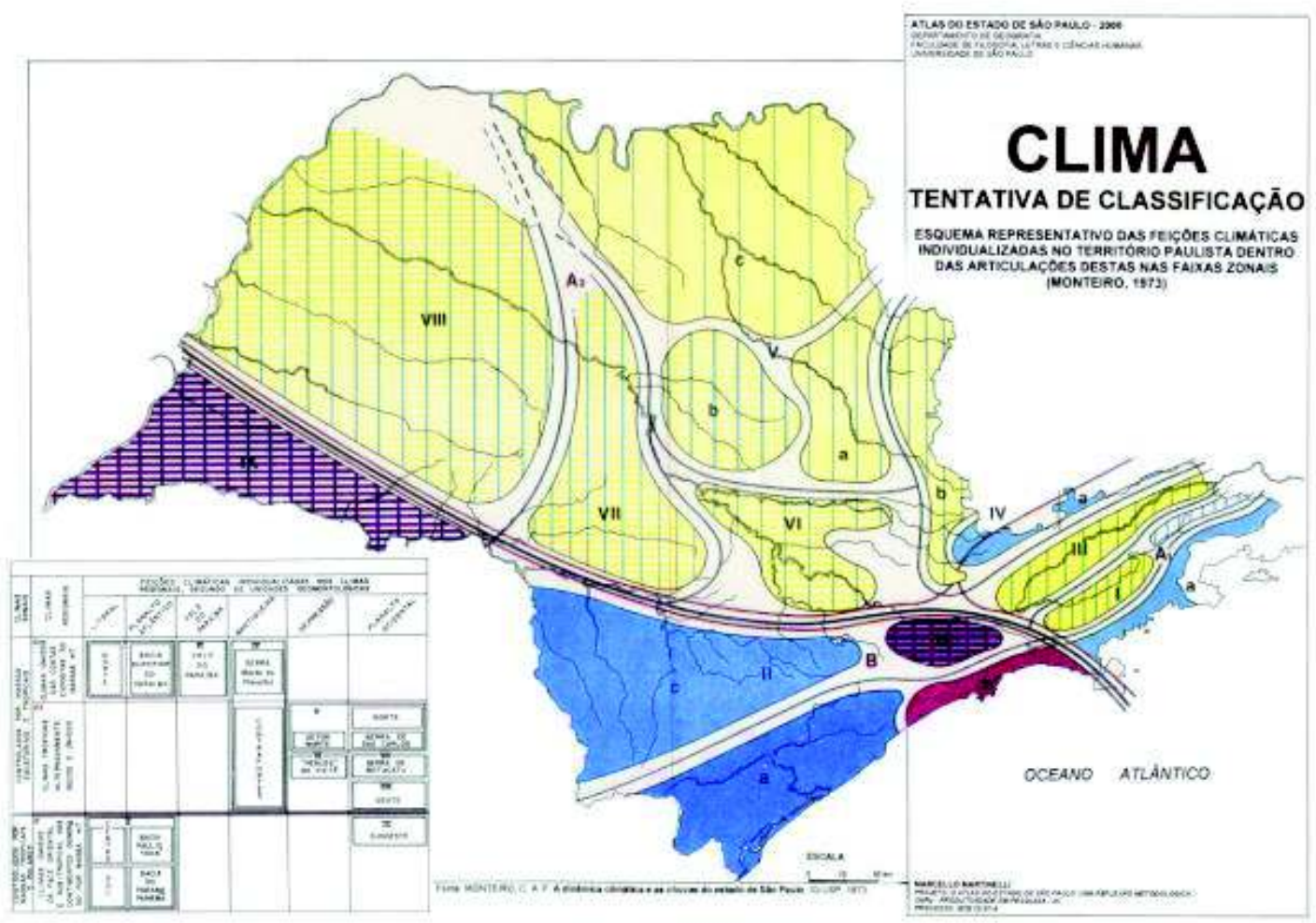

Figura 12: Mapa do clima do estado de São Paulo, elaborado por Monteiro, 1975. Fonte: Martinelli, 2010. 


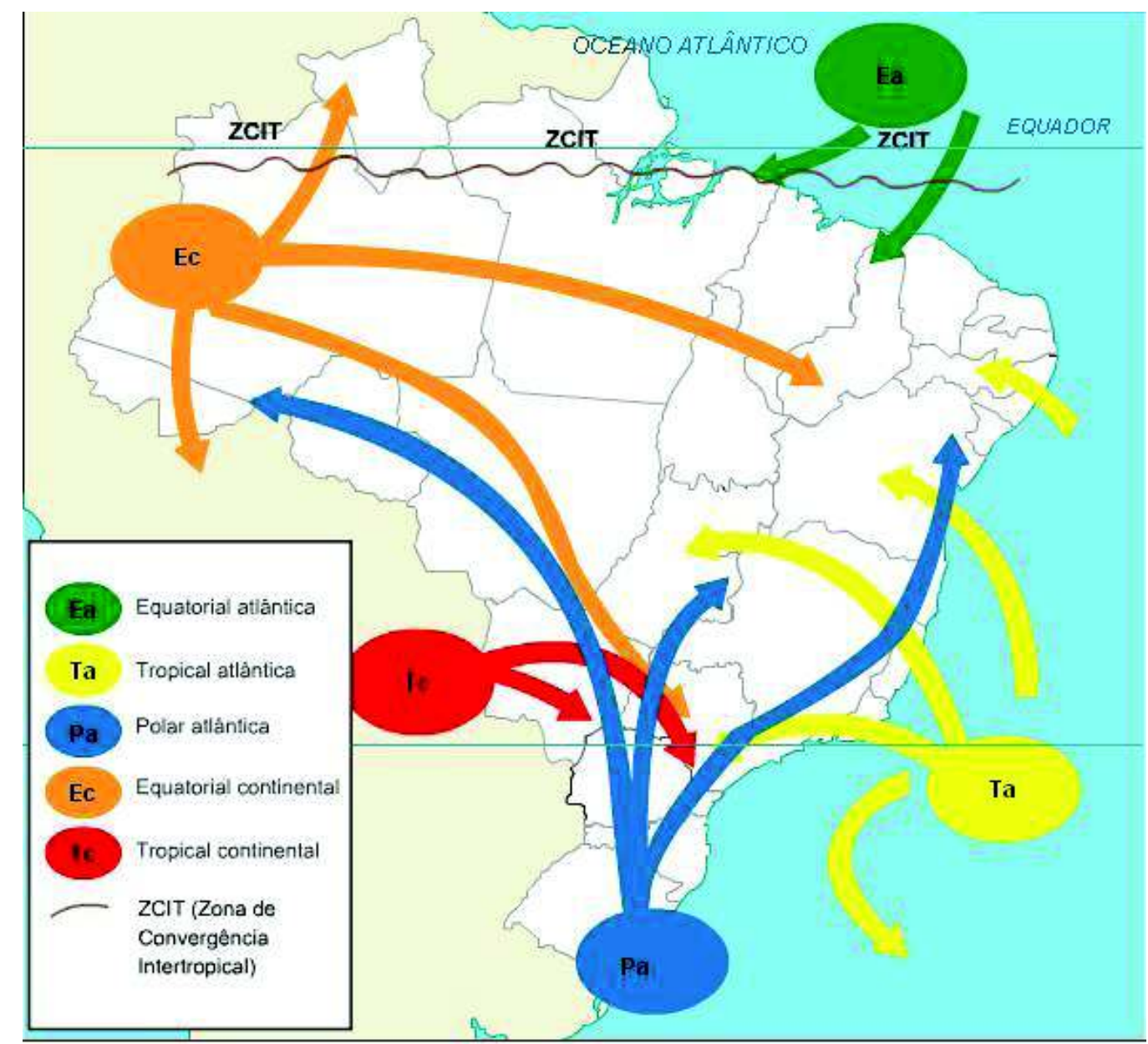

Figura 13: Mapa dos sistemas atmosféricos atuantes no Brasil.

Fonte: Atlas Geográfico do Brasil, Editora Melhoramentos. 1992.

\section{CONSIDERAÇÕES FINAIS}

Como se pôde perceber pela exposição aqui apresentada, a cartografia climatológica abarca todo um leque possível de representações cartográficas temáticas. Com exceção do advento da interação, da acessibilidade e da maleabilidade permitidas pelo meio digital, nada é novo no tocante às regras para construção de mapas climáticos.

Os mapas climáticos (e meteorológicos) retratam, essencialmente, dados que possuem relações de ordem (hierarquia) ou de seletividade. Devem, portanto, adotar a escolha correta das variáveis visuais, de forma a expressar relações visuais de mesma natureza, ou seja, ordenadas ou seletivas, respectivamente. No caso das representações ordenadas, convém relembrar que as relações de ordem podem ser tanto de natureza quantitativa (pelo trabalho com dados numéricos agrupados em intervalos de valores) quanto de natureza qualitativa (quando a hierarquia se expressa sem a existência de valores numéricos).

Atualmente, os SIG existentes, que permitem o processamento de dados climáticos e criação de representações cartográficas, em geral disponibilizam ao usuário uma gama de possibilidades na escolha de cores, símbolos, texturas etc. A automatização dos procedimentos, contudo, pode levar à escolha incorreta dos signos, pelo desconhecimento ou desconsideração das regras estabelecidas para a Cartografia Temática como um todo. O mesmo pode ser dito em relação aos mapas digitais disponíveis em websites, que ampliam consideravelmente a acessibilidade à produção cartográfica sobre o clima, mas devem ser avaliados não apenas pelos conteúdos que representam, mas também à luz dos preceitos oriundos da Semiologia Gráfica, conforme discutido no presente trabalho. 
Portanto, cabe ao profissional da área da Climatologia, interessado na utilização ou concepção de mapas dessa área do conhecimento, atentar-se para as regras existentes. Se tais regras não se configuram como convenções cartográficas, tampouco devem ser desconsideradas, pois são fruto de longos anos, em inúmeros estudos, na busca por soluções coerentes para o emprego da linguagem visual na retratação de fenômenos com expressão geográfica - como é o caso do clima.

\section{REFERÊNCIAS BIBLIOGRÁFICAS}

BARROS, Juliana Ramalho; ZAVATTINI, João Afonso. Bases conceituais em climatologia geográfica. Mercator - Revista de Geografia da UFC, v. 08, n. 16, 2009. p. 255-261

BERTIN, Jacques. Sémiologie Graphique: les diagrammes, les réseaux, les cartes. Paris/La Haye: Monton \& Gauthier-Villars, 1967.

CONTI, José Bueno; FURLAN, Sueli Angelo. Geoecologia: o clima, os solos e a biota. In: ROSS, J. L. S. (Org.). Geografia do Brasil. São Paulo: Edusp, 1996.

GOIÁS (Estado). Secretaria de Indústria e Comércio. Superintendência de Geologia e Mineração. Caracterização Climática do Estado de Goiás. SILVA, Silvando Carlos da; SANTANA, Neiva Maria Pio de; PELEGRINI, José Cardoso. Goiânia, 2006.

MARTINELLI, Marcello. Clima do estado de São Paulo. Confins, São Paulo, n. 8, p. 2-16, 2010. Disponível em: $<$ http://confins.revues.org/index6348.html $>$. Acessado em jan. 2010.

MONTEIRO, Carlos Augusto de Figueiredo. Teoria e Clima Urbano. São Paulo: Universidade de São Paulo/ Instituto de Geografia, 1976. 181 p.(Série Teses e Monografias n 25).

COLE, Steve; LESLIE, John Leslie. NASAAnd NOAA Mark 50 Years Of Weather Watching From Space. April 01, 2010. Disponível em: <http://www.nasa.gov/home/hqnews/2010/apr/HQ_10-072_TIROS1_Anniversary.html>. Acesso em 12 set. 2010.

OLIVEIRA, Ivanilton José de. A linguagem dos mapas: utilizando a cartografia para comunicar. Revista Temporis (ação), Cidade de Goiás (GO), v. 1, n. 8, p. 37-62, 2005. Disponível em: <http://www.iesa.ufg. br/observatoriogeogoias/>.

ROBINSON, A. H.; MORRISON, J. L., MUEHRCKE, P. C., KIMERLING, A. J.; GUPTIL, S. C. Elements of cartography. 6. ed. New York: John Wiley and Sons, 1995.

SLOCUM, Terry A.; McMASTER, Robert B., KESSLER, Fritz C. Thematic Cartography and Geovisualization. New Jersey: Prentece Hall, 2009.

SORRE, Max. Objeto e método da climatologia. Tradução José Bueno Conti. Revista do Departamento de Geografia, n. 18, p. 89-94, 2006.

VIANELLO, Rubens Leite; ALVES, Adil Raimer. Meteorologia básica e aplicações. Viçosa: UFV, 2000. $449 \mathrm{p}$.

Trabalho enviado em janeiro de 2011

Trabalho aceito em maio de 2011 